\title{
Effects of a comprehensive cardiac rehabilitation program on quality of life and exercise tolerance in women: $A$ retrospective analysis
}

\author{
Michael D Kennedy*1, Mark Haykowsky¹, Bill Daub², Karen van Lohuizen², \\ Grant Knapik ${ }^{2}$ and Bill Black ${ }^{2}$
}

Address: ${ }^{1}$ Faculty of Rehabilitation Medicine, University of Alberta, Edmonton, Alberta, Canada and ${ }^{2}$ Northern Alberta Cardiac Rehabilitation Program, Glenrose Rehabilitation Hospital, Capital Health, Edmonton, Alberta, Canada

Email: Michael D Kennedy* - kennedy@ualberta.ca; Mark Haykowsky - mark.haykowsky@ualberta.ca; Bill Daub - bdaub@cha.ab.ca; Karen van Lohuizen - kvanlohu@cha.ab.ca; Grant Knapik-gknapik@cha.ab.ca; Bill Black - bdaub@cha.ab.ca

* Corresponding author

Published: I April 2003

Current Controlled Trials in Cardiovascular Medicine 2003, 4:I

This article is available from: http://crm.controlled-trials.com/content/4/I/I

(C) 2003 Kennedy et al; licensee BioMed Central Ltd. This is an Open Access article: verbatim copying and redistribution of this article are permitted in all media for any purpose, provided this notice is preserved along with the article's original URL.
Received: 8 December 2002

Accepted: I April 2003

\begin{abstract}
Background: Currently, there are a lack of investigations that have examined the effect of participating in a comprehensive cardiac rehabilitation program on quality of life and physiological measures in women of different ages. The purpose of this investigation was to examine the effect of participating in a comprehensive cardiac rehabilitation program on quality of life, exercise tolerance, blood pressure and lipids in women between 33 and 82 years of age.

Methods: The 126 women participated in a I4-week cardiac rehabilitation program that consisted of 7 weeks of formal supervised exercise training and 7 weeks of unsupervised exercise and lifestyle modification. Physiologic and quality of life outcome measures obtained at the outset and after 14 weeks included: I) exercise treadmill time; 2) resting and peak systolic and diastolic blood pressure; 3) total cholesterol, low-density lipoprotein cholesterol, high density lipoprotein cholesterol and Triglycerides; 4) Cardiac Quality of Life Index questionnaire.

Results: Significant improvements were found in the following quality of life measures after participating in the cardiac rehabilitation program: physical well being, psychosocial, worry, nutrition and symptoms. No significant differences were seen for any QOL variable between the different age groups. Significant improvements were seen in exercise tolerance $(+21 \%)$ and high density lipoprotein (+5\%).

Conclusion: Cardiac rehabilitation may play an important role in improving quality of life, exercise tolerance and high density lipoprotein cholesterol levels in younger and older women with underlying cardiovascular disease.
\end{abstract}

\section{Background}

Improvement in quality of life (QOL) is an important goal for individuals participating in outpatient cardiac rehabilitation (CR) programs.[1] Despite this importance, traditional CR programs have focused primarily on improving exercise tolerance and risk factor modification with less emphasis being placed on improving overall QOL.[2] Previous investigations have shown an 
Table I: Subject characteristics

\begin{tabular}{|c|c|c|c|c|c|}
\hline Age (years) & \multicolumn{5}{|c|}{$61 \pm 12$ years } \\
\hline Height (m) & \multicolumn{5}{|c|}{$1.6 \pm 0.06$} \\
\hline Weight & \multicolumn{3}{|c|}{ Pre: $72.9 \pm 15.3$} & \multicolumn{2}{|c|}{ Post: $71.4 \pm 15.2$} \\
\hline \multirow{6}{*}{ Type of event: (number) } & \multicolumn{5}{|c|}{ Myocardial Infarction: 57} \\
\hline & \multicolumn{5}{|c|}{ Coronary Artery Bypass: 26} \\
\hline & \multicolumn{5}{|c|}{ Angioplasty: 17} \\
\hline & \multicolumn{5}{|c|}{ Valve Surgery or Problems: 8} \\
\hline & \multicolumn{5}{|c|}{ CAD (including angina): 6} \\
\hline & \multicolumn{5}{|c|}{ Other: 12} \\
\hline \multirow[t]{5}{*}{ Cholesterol (mmol/L) } & \multicolumn{3}{|l|}{ Pre } & \multicolumn{2}{|l|}{ Post } \\
\hline & \multicolumn{3}{|c|}{ Total : $5.38 \pm 1.08$} & \multicolumn{2}{|c|}{ Total: $5.40 \pm 1.02$} \\
\hline & \multicolumn{3}{|c|}{ LDL: $3.23 \pm 0.90$} & \multicolumn{2}{|c|}{ LDL: $3.25 \pm 0.94$} \\
\hline & \multicolumn{3}{|c|}{ HDL: $|.20 \pm 0.3|$} & \multicolumn{2}{|c|}{ HDL: $1.26 \pm 0.32 *$} \\
\hline & \multicolumn{3}{|c|}{ Triglyceride: $2.03 \pm 0.93$} & \multicolumn{2}{|c|}{ Triglyceride: $1.95 \pm 0.77$} \\
\hline \multirow[t]{4}{*}{ Blood Pressure $(\mathrm{mm} / \mathrm{Hg})$} & \multicolumn{3}{|c|}{ Diastolic: } & \multicolumn{2}{|c|}{ Systolic } \\
\hline & & Rest & Max & Rest & Max \\
\hline & Pre: & $77.4 \pm 9.8$ & $86.0 \pm 12.4$ & $|3| .9 \pm 28.2$ & $168.7 \pm 25.4$ \\
\hline & Post: & $76.3 \pm 10.2$ & $83.5 \pm 9$ & $132.5 \pm 2.6$ & $166.9 \pm 23.6$ \\
\hline $\begin{array}{l}\text { Exercise Tolerance Time } \\
\text { (minutes) }\end{array}$ & Pre: 6 & & & Post: $8.0 \pm 2$ & \\
\hline
\end{tabular}

(All values are mean $\pm \mathrm{SD}$; $* \mathrm{P}<0.05$ vs. Pre)

improvement in QOL after participating in a CR program. [3-11] However, a limitation of these investigations was the small sample size and the scarcity of older women who participated as study subjects. These limitations are due, in part, to the reluctance of physicians to refer older women to CR programs[10,12]. Paradoxically, older women with cardiovascular disease have markedly reduced exercise capacity and a higher disability rate compared to older males [13] and as a consequence may derive the greatest benefits from participating in a comprehensive CR program.[14] Therefore, CR programs may be of extreme benefit in attenuating the age-mediated decline in cardiorespiratory fitness[15], cardiovascular disease disability.[13] and disturbed mood states after a cardiovascular event $[16,17]$. resulting in an overall improvement in QOL. Currently, there is a paucity of investigations that have examined the effects of participating in a comprehensive CR program on QOL in women. The purpose of this investigation was to examine the effect of participating in a comprehensive CR program on QOL, exercise tolerance, blood pressure and lipid profiles in women. A secondary objective was to examine the effects of aging on the above outcome measures.

\section{Methods Subjects}

The subjects for this retrospective investigation were 126 women (mean \pm SD: $61 \pm 12$ yrs) who participated in the Northern Alberta Cardiac Rehabilitation Program between 1995-1999 (Table 1). Subjects were grouped, into the following age categories: $30-49$ years $(15 \%), 50-59$ years $(24 \%), 60-69$ years $(37 \%)$ and $>70$ years $(24 \%)$.

\section{Baseline orientation and program design}

The subjects attended an orientation session that consisted of education classes and an initial visit with a designated nursing case manager. Subsequent referrals to a dietician, social worker, physical or occupational therapist were scheduled as required. The initial symptom-limited graded exercise test was used to prescribe the aerobic exercise intensity. The overall program consisted of 7 weeks of formal supervised exercise training and 7 weeks of exercise training and lifestyle behaviour modification on their own.

\section{Exercise tolerance testing and lipid profiles}

Incremental exercise tolerance testing (ETT) was performed using the Bruce or modified Bruce treadmill protocols.[15] Subjects performed the same protocol on both 
Table 2: The 20-Item Quality of Life Instrument with difference score*t for each QOL measure $(\mathrm{N}=126)$

\begin{tabular}{|c|c|c|}
\hline Domain & Questions pertaining to each domain & Difference score (mm); P-value \\
\hline \multirow[t]{9}{*}{ Psychosocial Well Being } & 6. Is your sexual activity sufficient to meet your needs? & I.7; NS \\
\hline & 8. How easy is it to adjust to your heart condition? & $7.6 ; P<0.02$ \\
\hline & 9. How much fun do you have (hobbies, recreation etc.)? & 5.4; $P<0.05$ \\
\hline & 13. How useful do you feel? & $6.5 ; P<0.01$ \\
\hline & 14. How much happiness do you feel? & $3 ;$ NS \\
\hline & 15. How satisfying is your life? & $2.2 ; \mathrm{NS}$ \\
\hline & 18. How good is the quality of your life? & 3.I; NS \\
\hline & $\begin{array}{l}\text { 19. Is your level of contact with your friends and family sufficient to meet } \\
\text { your needs? }\end{array}$ & $3.5 ; \mathrm{NS}$ \\
\hline & 20. Do you feel rejected by your family or loved ones? & I.5; NS \\
\hline \multirow[t]{4}{*}{ Physical Well Being } & I. How much strength do you have? & $8.1 ; P<0.01$ \\
\hline & 3. Do you tire easily? & $-8.4 ; P<0.01$ \\
\hline & 7. How is your present state of health? & $7.3 ; \mathrm{P}<0.01$ \\
\hline & II. How much can you work at your usual tasks (housework, office)? & $|5.2 ; P<0.0|$ \\
\hline \multirow[t]{2}{*}{ Symptom } & 16. How much heart pain do you feel? & $-3.9 ; P<0.05$ \\
\hline & 17. How often do you feel heart pain? & $-4.5 ; P<0.05$ \\
\hline \multirow[t]{2}{*}{ Nutrition } & I0. Do you find eating a pleasure? & $4.5 ; \mathrm{P}<0.05$ \\
\hline & 12. Is the amount you eat sufficient to meet your needs? & $0.7 ;$ NS \\
\hline \multirow[t]{3}{*}{ Worry } & 2. Is the amount of time you sleep sufficient to meet your needs? & $5.7 ; \mathrm{P}<0.01$ \\
\hline & 4. Do you feel your present weight is a problem? & $3.9 ; \mathrm{NS}$ \\
\hline & 5. Do you feel worried about your heart condition? & $-9.2 ; P<0.01$ \\
\hline
\end{tabular}

* Difference score $=$ Post CR score minus the Pre CR score expressed in millimetres; $\dagger$ a negative difference score indicates a decrease in the measure after $C R$ compared to before $C R$

initial and post CR time periods. Systolic and diastolic blood pressures were acquired at rest and during exercise. Lipid profiles included total cholesterol, low-density lipoprotein cholesterol (LDL), high-density lipoprotein cholesterol (HDL) and triglycerides (TG). The above outcome measures were acquired at the outset and 14 weeks after the start of the CR program.

\section{Exercise training program}

Aerobic training was performed 2-3 days/week at an intensity of $70-85 \%$ maximal heart rate for 40 minutes ( 10 minutes warm-up/cool down plus 30 minutes of treadmill walking or cycle ergometers). To ensure patient safety, continuous ECG (telemetry) and intermittent blood pressure measurements were acquired while exercising during the first 2 weeks of training. Subjects were also encouraged to perform "unsupervised" home exercise training (totalling 4-5 days/week) after completing the second week of the program. Approximately $25 \%$ to $30 \%$ of the patients were also prescribed light to moderate resistance training as part of their program. More specifically, after completing 4-6 aerobic training sessions, patients performed two circuits (10 repetitions/set) using the following exercises on weight-training machines (seated chest press, lateral pull downs, shoulder press, vertical row, triceps extensions and arm curls) or using free weights (chest flys, pullovers, side raises, bent over flys, arm curls and tricep extensions). Patients were encouraged to gradually increase the number of repetitions to 15 before a third circuit was added. Finally, as part of the overall program, a series of 5 weekly education classes that addressed a wide variety of heart-health lifestyle topics was provided.

\section{Assessment of QOL}

QOL was assessed using the Cardiac Quality of Life Index, a multifaceted cardiac disease-specific 20 question visual analogue scale[18] (Table 2), at baseline orientation and 14 weeks later.

\section{Statistical analysis}

A repeated measures ANOVA was used to assess the effects of the CR program on QOL, ETT, resting and exercise blood pressure, total cholesterol, LDL, HDL and TG. A two-way (training by age) repeated measures ANOVA was used to assess differences in the above mentioned outcome measures using the previously described four different age sub-groups. Ethics approval for this investigation 


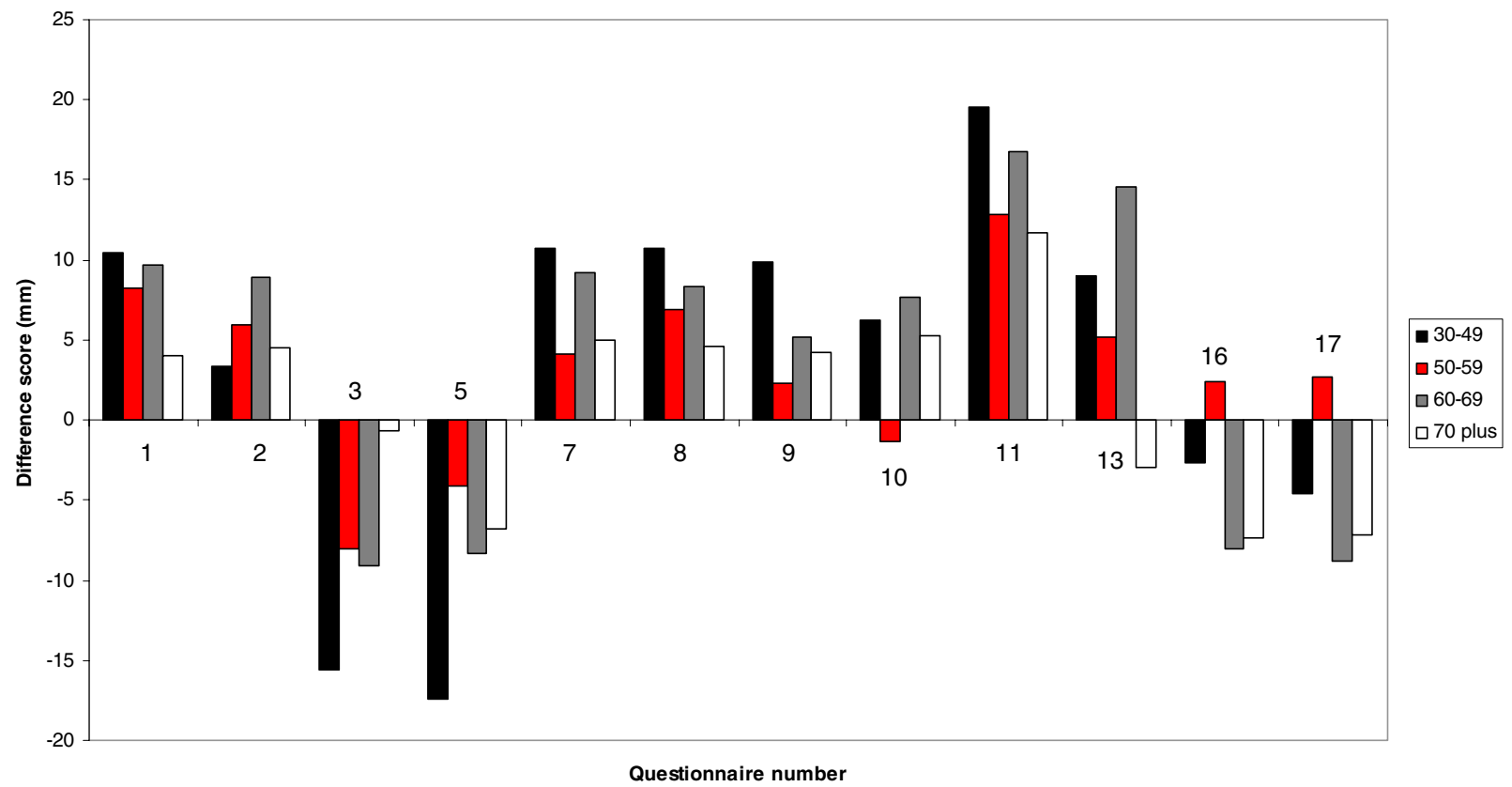

Figure I

Actual change in significant QOL measures for each age group

was obtained from the medical ethics committee at the University of Alberta and Capital Health.

\section{Results}

\section{Program}

The mean duration of the formal supervised exercise training and lifestyle behaviour modification program was 6.7 \pm 2.4 weeks and included an average of 11 exercise classes and 11 education classes.

\section{Quality of life}

The comprehensive CR program resulted in a significant improvement in the following QOL measures: 1) Physical well being measures including: strength (Question [Q]1), fatigue (Q3); health status (Q7), and how much they could work at usual tasks (Q11); 2) Psychosocial measures including: better adjustment to their heart condition (Q8), perceived fun (Q9), and feelings of useful- ness (Q13); 3) Worry and nutrition measures including: more pleasure when eating (Q10), satisfaction with amount of sleep (Q2), and worried less about their heart condition $(\mathrm{Q} 5)$; 4) Reduction in their symptoms including: the intensity of heart pain (Q16), and frequency of heart pain (Q17). No significant change was found for any other QOL measure. Difference scores (Post CR score minus Pre CR score) for all QOL measures are presented in Table 2 with $P$ values.

No significant differences were found for any QOL measure between the four different age groups before or after the CR program. Figure 1 presents significant QOL measures grouped by question for each age group. Irrespective of age, the greatest overall change $(+31 \%)$ in all of the QOL measures was found for question 11 ("How much can you work at your usual tasks?). 


\section{Physiological measures}

Exercise tolerance time $(+21 \%)$ and HDL $(+5 \%)$ cholesterol improved significantly after the CR program with no significant alteration in resting or peak exercise, systolic and diastolic blood pressure, total cholesterol, LDL cholesterol or TG (Table 1).

\section{Discussion}

The major new finding of this investigation is that a comprehensive CR program resulted in an improvement in physical, psychosocial, worry, nutrition, and symptom domains of QOL in younger and older women. The relative improvement in the perception of one's strength $(+16 \%)$, how much one can work at usual tasks $(+31 \%)$ and how much one tires $(-15 \%)$ provides preliminary evidence that CR may play an important role in improving individuals perception of their physical capacity. Previous investigations have found similar improvements in selfreported physical activity-physical ability[9], and physical functioning[5] in younger and older males and females, as well as improved energy and function after participating in a CR program[19] (in depressed and non-depressed women). Our findings suggest that a comprehensive CR program not only improves exercise tolerance (objectively measured during an incremental ETT) but also that women perceive that they can do more tasks (jobs), fatigue less and return to an active lifestyle. Ades[20] recently found that the main determinants of self-reported physical function in men and women with underlying cardiovascular disease include peak aerobic capacity and depression score. This finding reinforces that both physical and psychosocial factors are important goals in maintaining physical function in individuals with cardiovascular disease. More importantly, these goals may become more important for older women who, due to aging, underlying disease and disuse associated with a sedentary lifestyle, have markedly reduced exercise capacity that results in increased disability.

Our finding that psychosocial, worry, nutrition, and symptom domains improved after the CR program are consistent with previous investigations. $[4,5,8,9,19]$ Since depression, anxiety, worry and social isolation are not uncommon in individuals participating in CR programs $[17,19,21]$ a major goal of these programs should be to alleviate some of these symptoms. In the present investigation, we found that subjects worried less about their condition, improved their adaptation to their heart condition and had an increase in fun activities, quality of sleep and greater pleasure while eating. Therefore, it may be possible that a comprehensive CR program could attenuate the psychological stress associated with underlying cardiovascular disease and, as a result, could improve overall QOL[19]

\section{Exercise capacity and lipid levels}

Our finding that ETT and HDL cholesterol improved after training is similar to that previously reported by others $[11,19,22]$. The improvement in ETT, combined with the perception that one can work more intensely at usual tasks, may suggest that participating in a comprehensive CR program may allow activities of daily living to be performed with greater ease. This salient finding is of extreme importance for older women who are more likely to be living alone[20], and who, as a result of the aging process, have reduced functional independence. Therefore, the enhanced exercise capacity may allow older women with underlying cardiovascular disease to become more functionally independent in their environment.

Our finding of an increase in HDL cholesterol after the CR program is extremely important, as lipid normalization is well known to reduce additional coronary events and mortality.[2] The lack of change in other blood lipids and resting and peak exercise systolic and diastolic blood pressures may be due to the duration of time that subjects participated in the formal part of the program $(<2$ months of supervised exercise training). These findings are similar to previous investigations that found favourable improvements in HDL cholesterol levels with no change in other blood lipid values after 12 weeks of a formal supervised training program.[11,19]

\section{Limitations}

The retrospective nature of this investigation, the lack of a control group and the length of unsupervised training ( 7 weeks) are all major methodological factors that limit the strength of our findings. However, the results of this investigation are of importance due to the paucity of women (especially older women) who are referred to cardiac (exercise) rehabilitation programs combined with the exclusion of older women in the majority of previous cardiac rehabilitation-intervention investigations. Moreover, our findings suggest that irrespective of age, women who participate in a CR program can improve their exercise tolerance and, as a result of this improvement, perceive that they are stronger, fatigue less and can do more work while performing their usual tasks. These findings suggest that future investigations should include women, in particular older women, as study participants in cardiac rehabilitation research investigations.

\section{Conclusions}

A short-term comprehensive CR program as performed by younger and older women resulted in a significant improvement in QOL measures including: worry/nutrition, physical well-being, psychosocial factors and symptoms. CR can play an important role in improving functional independence in all age groups of women, including older women with cardiac disease. Moreover, the improved ex- 
ercise capacity may result in a concomitant improvement in the ability to perform activities of daily living given that the women in this investigation, irrespective of age, felt less fatigued and perceived that they could do more work while performing their usual tasks.

\section{Competing interests}

None declared.

\section{Authors' contributions}

Author MDK designed the investigation, performed the statistical analysis and interpretation of the results, as well as participated in the preparation of the manuscript.

Author $\mathrm{MH}$ assisted with the statistical analysis, interpretation of the results and preparation of the manuscript.

Author BD generated the raw data, managed the database of patient records and participated in the editorial review and preparation of the manuscript.

Author KvL managed the cardiac rehabilitation program involved in the study, oversaw the lifestyle modification and assisted with the preparation of the manuscript.

Author GK performed the exercise training and management of the subjects exercise rehabilitation program.

Author BB supervised all clinical exercise assessment for both the intake and outtake of the program.

All authors read and approved the final manuscript.

\section{References}

I. Ades PA and Coello CE Effects of exercise and cardiac rehabilitation on cardiovascular outcomes Med Clin North Am 2000, 84:25I-2xi

2. Ades PA Cardiac rehabilitation and secondary prevention of coronary heart disease N Engl J Med 200I, 345:892-902

3. Oldridge N, Guyatt G, Jones N, Crowe J, Singer J, Feeny D, McKelvie $R$, Runions J, Streiner D and Torrance G Effects on quality of life with comprehensive rehabilitation after acute myocardial infarction Am J Cardiol 1991, 67:1084-1089

4. Beniamini Y, Rubenstein JJ, Zaichkowsky LD and Crim MC Effects of high-intensity strength training on quality-of-life parameters in cardiac rehabilitation patients Am J Cardiol 1997, 80:84I-846

5. Berkhuysen MA, Nieuwland W, Buunk BP, Sanderman R, Viersma JW and Rispens $P$ Effect of high versus low frequency exercise training in multidisciplinary cardiac rehabilitation on health related quality of life $J$ Cardiopulm Rehabil 1999, 19:22-28

6. Oldridge N, Gottlieb M, Guyatt G, Jones N, Streiner D and Feeny D Predictors of health-related quality of life with cardiac rehabilitation after acute myocardial infarction J Cardiopulm Rehabil 1998, 18:95-103

7. Dugmore LD, Tipson RJ, Phillips MH, Flint EJ, Stentiford NH, Bone MF and Littler WA Changes in cardiorespiratory fitness, psychological wellbeing, quality of life, and vocational status following a 12 month cardiac exercise rehabilitation programme Heart 1999, 81 1:359-366

8. Lavie CJ and Milani RV Effects of cardiac rehabilitation and exercise training on exercise capacity, coronary risk factors, behavioral characteristics, and quality of life in women $\mathrm{Am}$ j Cardiol 1995, 75:340-343
9. StAhle A, Mattsson E, Ryden L, Unden A and Nordlander R Improved physical fitness and quality of life following training of elderly patients after acute coronary events. A I year followup randomized controlled study Eur Heart J I999, 20: I 475- I484

10. Ades PA, Waldmann ML, Polk DM and Coflesky JT Referral patterns and exercise response in the rehabilitation of female coronary patients aged greater than or equal to 62 years $\mathrm{Am}$ J Cardiol 1992, 69:1422-1425

II. Lavie CJ and Milani RV Effects of cardiac rehabilitation, exercise training, and weight reduction on exercise capacity, coronary risk factors, behavioral characteristics, and quality of life in obese coronary patients Am J Cardiol 1997, 79:397-40 I

12. Ades PA, Waldmann ML, McCann WJ and Weaver SO Predictors of cardiac rehabilitation participation in older coronary patients Arch Intern Med 1992, I 52:1033-1035

13. Pinsky JL, Jette AM, Branch LG, Kannel WB and Feinleib $M$ The Framingham Disability Study: relationship of various coronary heart disease manifestations to disability in older persons living in the community Am J Public Health 1990, 80:13631367

14. Williams MA, Fleg JL, Ades PA, Chaitman BR, Miller NH, Mohiuddin $S M$, Ockene IS, Taylor CB and Wenger NK Secondary prevention of coronary heart disease in the elderly (with emphasis on patients > or $=75$ years of age): an American Heart Association scientific statement from the Council on Clinical Cardiology Subcommittee on Exercise, Cardiac Rehabilitation, and Prevention Circulation 2002, 105: $1735-1743$

15. American College of Sports Medicine ACSM's Guidelines for Exercise Testing and Prescription, Sixth Edition Baltimore, Lippincott, Williams \& Wilkins 2000, 6: I-368

16. Shephard RJ, Kavanagh $T$ and Klavora $P$ Mood state during postcoronary rehabilitation J Cardiopulm Rehabil 1985, 5:480-484

17. Kavanagh T, Shephard RJ and Tuck JA Depression after myocardial infarction Can Med Assoc ] 1 975, I I 3:23-27

18. Rukholm E, McGirr M and Potts J Measuring quality of life in cardiac rehabilitation clients Int J Nurs Stud 1998, 35:2 10-216

19. Lavie CJ, Milani RV, Cassidy MM and Gilliland YE Effects of cardiac rehabilitation and exercise training programs in women with depression Am J Cardiol 1999, 83: I 480-3, A7

20. Ades PA, Savage PD, Tischler MD, Poehlman ET, Dee J and Niggel J Determinants of disability in older coronary patients Am Heart J 2002, 143:151-156

21. Frasure-Smith N, Lesperance F, Gravel G, Masson A, Juneau M, Talajic $M$ and Bourassa MG Social support, depression, and mortality during the first year after myocardial infarction Circulation 2000, 101:1919-1924

22. Miller TD, Balady GJ and Fletcher GF Exercise and its role in the prevention and rehabilitation of cardiovascular disease Ann Behav Med 1997, 19:220-229

Publish with Bio Med Central and every scientist can read your work free of charge

"BioMed Central will be the most significant development for disseminating the results of biomedical research in our lifetime. "

Sir Paul Nurse, Cancer Research UK

Your research papers will be:

- available free of charge to the entire biomedical community

- peer reviewed and published immediately upon acceptance

- cited in PubMed and archived on PubMed Central

- yours - you keep the copyright 